\title{
Clinical Trials under the New European Regulation: An Update
}

\section{Andre den Exter}

Health law, Erasmus University Rotterdam, Rotterdam, Netherlands

Regulating clinical trials has a relatively short history in the European Union (EU). Already in 1995, the European Commission launched the idea to simplify and streamline the variety of approval and monitoring procedures of clinical trials in the EU member states. It took about nine years since the Clinical Trials Directive came into force, implementing good clinical practice (GCP) into national legislation. The Directive introduced a regime aimed at protectingthe rights and safety of clinical trials' participants, and simultaneously, harmonizing the national administrative proceduresto start clinical trials in all member states (Preamble). Although the Directive has brought important improvements in the safety and ethical soundness of clinical trials in the EU, the divergent transposition and application let to an unfavorable regulatory regime for clinical research, which contributed to an increase of administrative costs and insurance fees, and a decrease of $25 \%$ of clinical trials in the period between 2007 and 2011 [1]. It would be wrong to attribute the fall of clinical trials exclusively to the Directive but it became clear it has hampered (directly and indirectly) clinical research in Europe.

In 2012, former European Commission Dalli submitted a proposal to modernize the European rules on clinical trials. The new Clinical Trials Regulation 536/2014 [2] will replace the current Directive and will enter into force on 28 May 2016. The Directive has been criticized for its unnecessary bureaucracy, high costs and lack of regulatory harmonization [3]. One of the improvements concerns the simplification of the authorization procedure of multinational trials. In the near future, multinational trials will target more specific patient populations, such as subgroups identified through genomic information. To include sufficient participants, it may be necessary to include all member states. In the past, EU member states misused the authorization process to introduce additional requirements. Under the new regime, countries will apply one submission procedure, instead of a 'patchwork' of 27 national regulatory frameworks. The same counts for the safety reporting procedures.

Despite several improvements, the Regulation did not change the 'two-tired' assessment procedure in which two distinct bodies are involved (authorization bodies and ethics committee). This artificial separation induces administrative burdens and cumbersome hurdles to conduct research [4]. Instead, an integrated assessment including both ethical and scientific aspects was not incorporated since this is a matter of internal organization of each member state.

The Regulation strengthens the responsibilities of the sponsor in case clinical trials are conducted in a third country, by establishing an EU contact person, and facilitating supervision and control. Moreover, the European Commission is entitled to control whether regulatory systems of third countries comply the Regulation's basic provisions on clinical trials (data submitted in the application dossier). But how effective are those auditssince it is unlikely that the Commission can enforce these inspections outside its jurisdiction! By transferring the conduct of (industry sponsored) clinical trials to emerging economies such as India and Brazil, collaboration by third country authorities will remain voluntary [5]. Without adequate enforcement mechanisms, ensuring the ethical and scientific integrity of clinical research remains doubtful.

\section{Publication History:}

Received: January 25, 2016

Accepted: June 15, 2016

Published: June 17, 2016

\section{Keywords:}

European Union, Good clinical practice, European Commission

Another striking issue of concern is the fact that the Regulation does not govern experimentation that does not involve intervention (so-called 'non-interventional' studies). A 'non-interventional' study is defined as a clinical study rather than a clinical trial, i.e. similar to an 'observational' study [6]. According to the authors, this concept is not clear and may cause confusion.

\section{Conclusion}

Although aimed at restoring Europe's competitiveness in clinical research and the development of innovative treatments and medicines, the new Clinical Trials Regulation still lacks some effective remedies to avoid duplication of clinical research and created some uncertainty by excluding certain experiments.

\section{Competing Interests}

The author declares that he has no competing interests.

\section{Acknowledgement}

This research was generously sponsored by the EU Jean Monnet+ programme

\section{References}

1. European Commission. Proposal for a Regulation of the European Parliament and of the Council on clinical trials on medicinal products for human use, and repealing Directive 2001/20/EC, July 17, 2012 COM(2012)369 final, p. 2-3.

2. Officially, EU Regulation 536/2014 of 16 April 2014 on clinical trials on medicinal products for human use, and repealing Directive 2001/20/EC.

3. Kenter $\mathrm{MJH}$, Cohen AF (2012) Re-engineering the European Union Clinical Trials Directive. The Lancet 379: 1765-1767.

4. Commission Staff Working Document. Impact assessment report on the revision of the "Clinical Trials Directive" 2001/20/EC, Brussels 17.7.2012 SWD(2012)200 final, vol. I, p. 21-23.

5. Glickman SW, McHutchison JG, Peterson ED, Cairns CB, Harrington RA, et al. (2009) Ethical and Scientific Implications of the Globalization of Clinical Research. N ENGL J Med 36: 816-823.

6. Heringaand Dute, 'The proposed EU-regulation on Clinical Trials on Medicinal Products: An Unethical Proposal?' (2013) 4 EJHL 347-362; at 349.

"Corresponding Author: Dr. Andre den Exter, Health law, Erasmus University Rotterdam, Rotterdam, Netherlands, E-mail: denexter@bmg.eur.nl

Citation: den Exter A (2016) Clinical Trials under the New European Regulation: An Update. Int J Clin Res Trials 1: 105. doi: https://doi.org/10.15344/2456$8007 / 2016 / 105$

Copyright: (c) 2016 den Exter. This is an open-access article distributed under the terms of the Creative Commons Attribution License, which permits unrestricted use, distribution, and reproduction in any medium, provided the original author and source are credited. 